\title{
High Current Density Chronopotentiometric Electrosynthesis and SEM Characterization of Hexanethiol-Monolayer-Protected Silver Planar Nanotriangles (Ag@C 6 SH)
}

\author{
DJafar Vatan Khah Dowlat Sara, ${ }^{1}$ Ahmad Rouhollahi, ${ }^{2}$ \\ Seied Mahdi Pourmortazavi, ${ }^{3}$ and Mojtaba Shamsipur ${ }^{4}$ \\ ${ }^{1}$ Faculty of Chemistry, College of Science, University of Tehran, Tehran 1417614411, Iran \\ ${ }^{2}$ Department of Chemistry, K. N. Toosi University of Technology, Tehran, Iran \\ ${ }^{3}$ Faculty of Material and Manufacturing Technologies, Malek Ashtar University of Technology, Tehran, Iran \\ ${ }^{4}$ Department of Chemistry, Razi University, Kermanshah, Iran \\ Correspondence should be addressed to Mojtaba Shamsipur; mshamsipur@yahoo.com
}

Received 5 October 2015; Accepted 19 November 2015

Academic Editor: Hua Zou

Copyright (C) 2016 DJafar Vatan Khah Dowlat Sara et al. This is an open access article distributed under the Creative Commons Attribution License, which permits unrestricted use, distribution, and reproduction in any medium, provided the original work is properly cited.

\begin{abstract}
This work reports for the first time electrosynthesis of hexanethiol capped silver nanotriangles cores (Ag@C $\mathrm{C}_{6} \mathrm{SH}$ NCs) by a rapid, clean, and simple Double Pulse Chronopotentiometric (DCP) method in nonaqueous media, using a Taguchi orthogonal array $\mathbf{L}_{8}$ design to identify the optimized experimental conditions. It was found that the size and shape of the product could be tuned by the current density, electrolysis time, electrode distance, and amount of $\mathrm{NaBH}_{4} \%$ used. The $\mathrm{Ag} @ \mathrm{C}_{6} \mathrm{SH}$ NCs in different shapes and sizes (in the range of 30 to $44 \mathrm{~nm}$ as an average estimation) were synthesized, under different experimental conditions. Finally, the as-prepared nanoclusters electrosynthesized at optimized conditions were characterized by SEM, XRD, and UV-Vis spectroscopy. The average particle size of the triangular/pyramidal shape $\left(\mathrm{Ag} @ \mathrm{C}_{6} \mathrm{SH} \mathrm{NCs}\right)$, obtained under optimized experimental conditions, was $30.5 \pm 2.0 \mathrm{~nm}$ but the majority of nanoparticles in $\mathrm{TC}_{3}$ SEM are so much finer.
\end{abstract}

\section{Introduction}

Over the last two decades, an increasing attention has been focused on nanoclusters, as part of nanostructural materials as almost monodispersed isolable nanoparticles that are usually of sizes $<2.0 \mathrm{~nm}$ to $100 \mathrm{~nm}$ in diameter $[1,2]$. This is because of the faith that nanoclusters possess emergent unprecedented unique properties so that they are widely used in different areas such as energy conversion and storage systems like solar cells, fuel cells, sensing, imaging, and catalysis, derived in part from the fact that these particles and their properties lie somewhere between those of bulk and single-particle species $[3,4]$. Such "strange morsels of matter" [5] have many fascinating potential uses, including quantum computers [6] and devices [7, 8], chemical sensors [9], light-emitting diodes [10], "ferrofluids" for cell separations [11], industrial lithography [12], and photochemical pattern applications such as flat-panel displays [13]. Nanoclusters have also significant potential as new types of higher activity and selectivity catalysts [14-21]. Metal nanoclusters are also special nanoarchitecture of atom arrangement consisting of several to hundreds of atoms including surface atoms and, due to the large surface-to-volume ratio, the so-called aspect ratio, exhibit exciting and yet poorly studied size dependent properties. They consisted of at least three up to a dozen or more atoms, usually coordinated by the neutral ligand molecules.

In order to prevent agglomeration, these nanosized entities have to be stabilized by ligand molecules or a whole plethora of "protecting shells." The resulting metal colloids can be redispersed in water ("hydrosols") or organic solvents ("organosols") [22, 23]. Among the noble metal clusters, silver nanoclusters (AgNCs) are well-known for their excellent optical property which is critical in many research 
fields [24]. Also, AgNCs can be bioconjugated with different biomolecules, for fluorescent labeling, molecular diagnostics, and medical therapies $[25,26]$. However, in the absence of stabilizing agents to reduce their surface energies, the synthesis of AgNCs in aqueous solutions is difficult due to the tendency of AgNCs to aggregate irreversibly [2729]. The surface properties of the nanoparticles might be varied in a wide range via surface modification by organic compounds with a range of functional groups which can form self-assembled monolayers (SAMs). Among various organic compounds, thiol-containing small molecules are the most commonly used stabilizers in the synthesis of metal nanoparticle due to their strong affinity and interaction with noble metals especially Au/Ag [30].

The present work is dealing with the latest experimental challenge for the electrosynthesis and characterization of silver nanocluster cores capped with hexanethiol $\left(\mathrm{C}_{6} \mathrm{SH}\right)$ shell through the electrochemical dissolution of silver rod in the presence of hexanethiol as a suitable stabilizing agent because of the strong affinity of thiol molecules for coordination in $\mathrm{Ag}$ atom within $\mathrm{Ag}_{n}(n=4)$ core. Electrochemical synthesis of nanoparticles is superior to the other methods due to its potential for preparation of highly pure NCs with the controlled size, shape, and morphology [24, 31, 32]. The main drawback of this method is impossibility of directly following the formation and growth of nanoclusters which limit the collection of mechanistic information. To the best of our knowledge, monodisperse metallic particles with size dispersivity $<5 \%$ by using two-phase and one-phase solution chemical synthesis have not yet been previously reported in the literature (this is only true for $\mathrm{TC}_{3}$ not the other TCs based on the SEM image feature size of it). In this work, we have checked different experimental conditions (TCs) using the Taguchi robust design and after comparing SEM images of obtained electrosynthesized silver nanoclusters, the best ones are selected as $\mathrm{TC}_{3}$ and $\mathrm{TC}_{8}$ without any similarity between them. The significant difference in SEM features and images is reasonable and interpretable because the surface and nanostructure of the same sacrificial anode (Ag) during a series of various experimental conditions is critically and irreversibly damaged and finally changed. Therefore, there is no repeatability and reproducibility in the SEM images of final electrosynthesized silver nanoclusters. Also, the similarity of SEM images obtained within different conditions is significantly very low. Also, hexanethiol capped silver nanoclusters were prepared by electrochemical synthesis to obtain particles of small core radius and improved monodispersity. The hexanethiol compound was used to achieve a low desorption rate and slow growth after nucleation. It is well known that the dynamic process allows control over the size and shape of nanocrystals [33].

\section{Experimental}

2.1. Chemicals, Solutions, and Methodology. A silver wire and a platinum rod with $99.9 \%$ purity, $0.5 \mathrm{~mm}$ diameter, and exposed length of about $5 \mathrm{~mm}$ were used as sacrificial anode and cathode (counter electrode), respectively. The electrodes were initially cleaned in piranha solution, including mixture of $30 \% \mathrm{H}_{2} \mathrm{O}_{2}$ and concentrated $\mathrm{H}_{2} \mathrm{SO}_{4}$ with the ratio of $1: 3$. Before the use of silver wire as anode, it was subjected to potential cycling between -0.4 and $1.5 \mathrm{~V}$ at a scan rate of $50 \mathrm{mVs}^{-1}$ in $0.1 \mathrm{M} \mathrm{H}_{2} \mathrm{SO}_{4}$ solution for about 20 cycles for the sake of electrochemical cleaning. The electrodes were kept parallel to each other in a distance of about 5 to $20 \mathrm{~mm}$ (the diameter of electrochemical cell) and then electrolysis was carried out in the solution under nitrogen purge and a constant magnetic stirring. Aqueous solution of $1 \mathrm{M} \mathrm{KCl}$ (Merck) in 18.3 M $\Omega$ Millipore deionized water (Younglin Korean Instruments from RIPPI) was mixed with $20 \mathrm{mM}$ hexanethiol $\left(\mathrm{C}_{6} \mathrm{SH}\right.$, Aldrich) dissolved in absolute ethanol (Merck) in equal volumes and the resulting solution was used as the electrolyte.

2.2. Electrochemical Dissolution and Apparatus. The nanoparticles were electrosynthesized by electrochemical dissolution of the silver electrode in either presence or absence of $1 \%(\mathrm{w} / \mathrm{v}) \mathrm{NaBH}_{4}$ (Aldrich) which is converted rapidly to nanoclusters in presence of hexanethiol. Electrochemical dissolution of the silver wire electrode as a sacrificial anode was carried out in a $25 \mathrm{~mL}$ electrochemical cell at ambient temperature (about $25^{\circ} \mathrm{C}$ ), while a temperature range of $55-75^{\circ} \mathrm{C}$ was used for the two-electrode configuration. The experiments were conducted at different controlled current densities of 0.5 and $0.9 \mathrm{~A} \cdot \mathrm{cm}^{-2}$ by using an AUTOLAB PGSTAT 30-Potentiostat/Galvanostat TYPE III (Metrohm) in the chronopotentiometry mode.

\subsection{Electrolysis Process (Chronopotentiometry at High Current} Densities). During the electrolysis process and dissolution of the anodic metal, continuous evolution of gases, mainly $\mathrm{O}_{2}$, at the surface of cathode was observed. After about 5 to $50 \mathrm{~s}$ from starting the electrolysis at the constant current density of $0.5 \mathrm{~A} \cdot \mathrm{cm}^{-2}$, the dark brownish particles that floated on the surface of electrolyte solution appeared. The electrolysis was continued for about 15 to $30 \mathrm{~min}$ for each experiment. At the end of process, a microdrop of $30 \%$ (v/v) $\mathrm{H}_{2} \mathrm{O}_{2}$ was added to the solution in order to reduce the possibly formed silver oxide, as a byproduct. Then, the floating particles on the surface of ethanol-water mixture (electrolyte) were extracted into the toluene to obtain a clear dark brown to black suspension. Thereafter, the nanoparticles were removed from the solvent under vacuum, purified by washing with ethanol repeatedly to remove excess $\mathrm{C}_{6} \mathrm{SH}$, and finally dried under vacuum. Before SEM imaging, the nanoparticles were redispersed in the organic solvent and the obtained suspension was passed through a $0.2 \mu \mathrm{m}$ filter. The characterization of the purified nanoparticles was carried out by SEM instrument (FE-SEM S4160 02 Hitachi) after gold vacuum sputtering for a specified time period of $7 \mathrm{~min}$.

The process uses a silver electrode together with a platinum rod located in deionized water with a small distance apart. The sacrificial silver anode serves as the metal (ions) source for silver nanoparticle formation in the water/ethanol/potassium chloride electrolyte solution. A low DC voltage ( 5 to $50 \mathrm{mV}$ ) is applied to the electrodes. In this electrochemical process, some of the silver cations in close 
proximity to the anode accept the electrons from the current passing through and are reduced to metallic atoms as silver zerovalent species $\left(n \mathrm{Ag}^{0} \rightarrow \mathrm{Ag}_{n}\right.$ core $)$, which attract each other by van der Waal's forces and thus form small metallic core-shell nanoclusters in the presence of hexanethiol as stabilizing agent $\left(n \mathrm{Ag}+m \mathrm{C}_{6} \mathrm{SH} \rightarrow \mathrm{Ag}_{n}\left(\mathrm{C}_{6} \mathrm{SH}\right)_{m}\right)$. Generally, the electrical current density causes $\mathrm{Ag}^{0}$ (metal) and $\mathrm{Ag}^{+}$ (ions) again to migrate from the electrode into the deionized water.

\section{Results and Discussions}

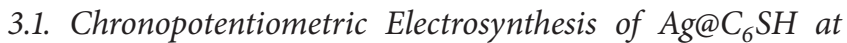
Constant Current Density. The electrochemical oxidation process by the galvanostatic method was carried out in a single compartment electrochemical cell at the constant currents of $0.5 \mathrm{~A}$. The cell consisted of $5 \mathrm{~mm}$ separated silver (sacrificial anode) and platinum (cathode) plates. Figure 1 shows the potential-time profiles ( $E$ - $t$ transients called double pulse chronopotentiograms) obtained for electrosynthesis of Ag@C 6 SH NCs during three successive 300 s cycles. Different colors show different cycles of chronopotentiometry: green: cycle 1 (1st $300 \mathrm{~s}$ ); blue: cycle 2 (2nd $300 \mathrm{~s}$ ); and red: cycle 3 (3rd $300 \mathrm{~s}$ ). As it is seen from Figure 1, in the course of applying the constant reduction current pulses, a decrease in potential is observed indicating that the metallic silver is being reduced. In all experiments, an almost stable potential value around $+10 \mathrm{~V}$ was achieved in the oxidation step, indicating that this is the lowest possible potential value in the electrolysis at which silver reduction occurs under the experimental conditions used. Alternatively, during the oxidizing step, a drastic increase of potential is perceived, which reveals that some of the silver atoms are oxidized instantaneously.

During electrolysis, the electrode surface changes seriously as a function of applied potential or current pulse. During the first cycle (green curve), it could be seen that, at the beginning of electrolysis (i.e., about first $10 \mathrm{~s}$ ), the $0.5 \mathrm{~A} \cdot \mathrm{cm}^{-2}$ current pulse causes the oxidization of silver atoms at the surface of sacrificial anode and, consequently, a drastic increase in the potential occurred, due to the corrosion of silver anode. About $10-15 \mathrm{~s}$ after starting the electrolysis, an immediate decrease in the voltage demonstrates the reduction of released silver cations in the solution and generation of zerovalent free atoms of silver $\left(\mathrm{Ag}^{0}\right)$ that are rapidly converted to primary particles as $\mathrm{Ag}_{n}$ (core), which practically control the critical nucleation step and can influence the final size dispersivity of the electrogenerated nanoclusters. Finally, in presence of hexanethiol, the thiol capped silver nanoclusters can be generated as core-shell nanostructures in the form of nanoclusters.

It should be noted that the presence of $\mathrm{NaBH}_{4}$ may accelerate the electroreduction stage in the electrosynthesis and the potential may change rapidly in the presence of this reactive reducing agent. The oxidation-reduction loop was repeated until the electrolysis progresses reached $25 \mathrm{~s}$ and then the potential remained more or less constant at $10 \mathrm{~V}$, which obviously shows that no additional redox

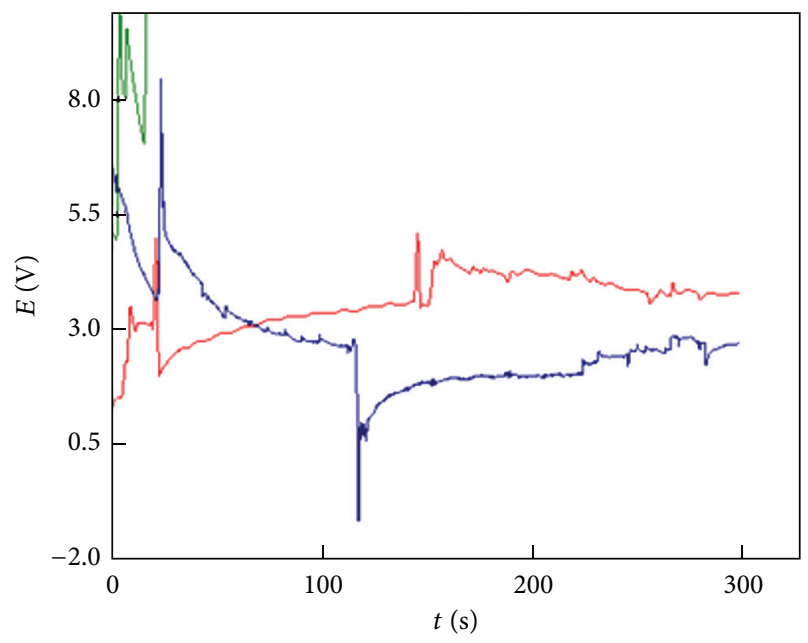

FIGURE 1: Constant current chronopotentiogram ( $E$ - $t$ transients) obtained during the galvanostatic electrosynthesis of $\mathrm{Ag} @ \mathrm{C}_{6} \mathrm{SH}$ at $j=0.5 \mathrm{~A} \cdot \mathrm{cm}^{-2}$. Silver rod, used as sacrificial anode electrode, and $\mathrm{Pt}$ rod, used as working electrode, were immersed in the electrolyte solution $\left(\mathrm{C}_{6} \mathrm{SH}+\mathrm{NaBH}_{4}+\mathrm{KCl}+\mathrm{EtOH}\right)$ under continuous nitrogen purge during three cycles: green: cycle 1 (1st $300 \mathrm{~s})$; blue: cycle 2 (2nd 300 s); red: cycle 3 (3rd 300 s).

reaction occurred and the surface of electrode is temporarily passivated, most probably due to formation of silver oxide layers.

During the second cycle (blue curve), the first shaking of the electrode which was followed by 3 min ultrasonication caused the release of the electrogenerated clusters from the surface and their falling into the solution. Thereafter, the heavy particles formed tended to settle down in the solution and the lighter particles begin to move to the surface which resulted in the formation of a nanoemulsion (or nanomicelle) of the nanoclusters. In the second cycle of electrolysis, during the first $25 \mathrm{~s}$, the potential again decreased mildly and then jumped to more than $8 \mathrm{~V}$ which elucidated that an oxidation step started again and the electrode surface is once more activated. This rapid increase in the potential was then followed by a mild decrease (in the range of 5.5 to $3.0 \mathrm{~V}$ ) for the next $100 \mathrm{~s}$ (usually called transition time $\tau$, the time period between two steep and sudden potential changes). This pattern approves the gradual reduction of the as-generated silver atoms. After $125 \mathrm{~s}$, a drastic decrease in the potential (from $3.0 \mathrm{~V}$ to $-1 \mathrm{~V}$ ) occurred which may be attributed to the reduction of all silver ions present in the electrolyte. In the rest of electrolysis, the surface of electrode is again partially passivated; thus, the oxidation of the anode surface was faced with more delay and showed slow kinetics so that there was no significant redox reaction occurring until the end of electrolysis. Admittedly, different crystal planes of the surface silver atoms can greatly affect the electroactivity of the surface during different cycles of the electrolysis. Surface change during $E$ - $t$ transients is inevitable and, after $125 \mathrm{~s}$ of electrolysis, the potential is firstly increased to $+3.0 \mathrm{~V}$ and then remained more or less constant for the last $150 \mathrm{~s}$ (no redox reaction occurring). 


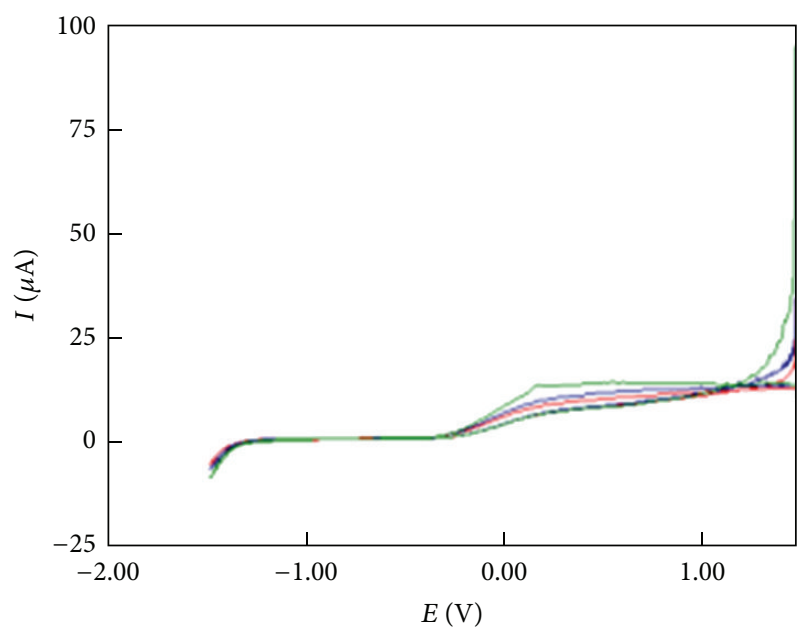

(a)

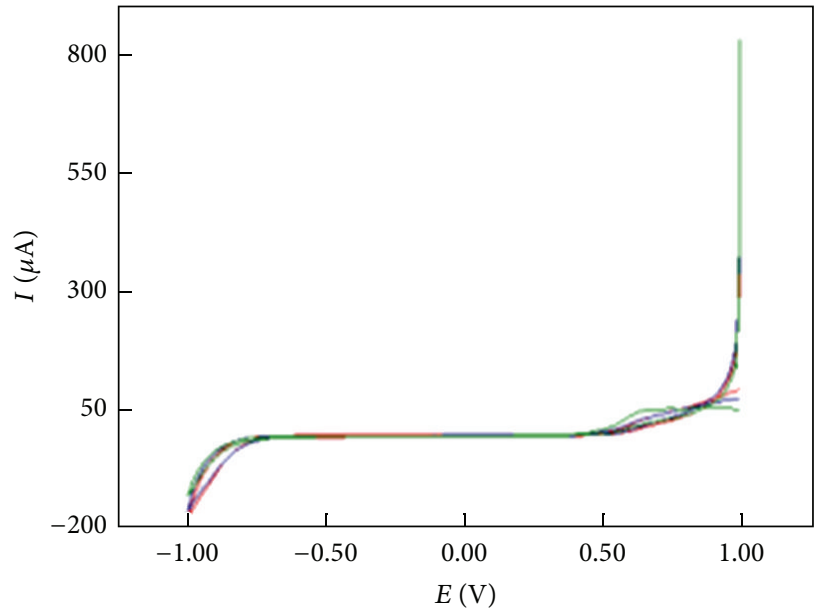

(b)

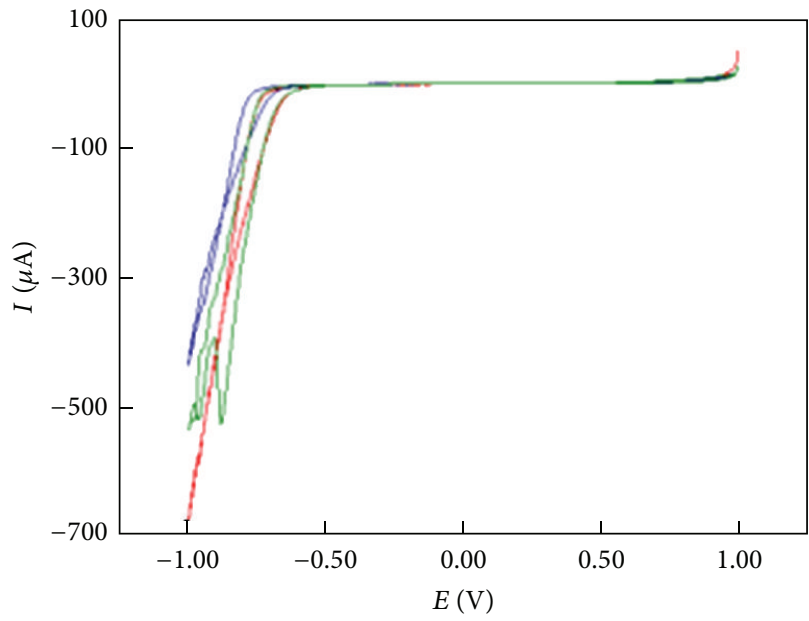

(c)

Figure 2: Cyclic voltammograms of electrolyte solution $\left(\mathrm{C}_{6} \mathrm{SH}+\mathrm{NaBH}_{4}+\mathrm{KCl}+\mathrm{EtOH}\right)$ at the $\mathrm{Ag}$ rod (a), GCE (b), and Pt electrode (c) surfaces under nitrogen purge before electrochemical synthesis under optimized electrosynthesis protocol at different scan rates: green: $25 \mathrm{mVs}^{-1}$; blue: $50 \mathrm{mVs}^{-1}$; red: $100 \mathrm{mVs}^{-1}$.

Finally, in the last cycle (red curve), no more significant redox reaction was observed which perceived that the electrode surface cannot be regenerated and refreshed again. In this case, only two mild potential jumps in about 25 and $150 \mathrm{~s}$ are observed.

Thus, based on the above-mentioned experiences, it can be concluded that, in the course of electrolysis, the surface of sacrificial anode electrode surface not only undergoes a simple electrocorrosion but also witnesses irreversible structural changes. Briefly, in the first cycle, the surface possesses the highest resistance to the redox reaction (very little $E$ change); during the second cycle, the surface is activated and gets ready to do electrolysis, so a fast kinetics can be observed; finally, in the last cycle, the surface is seriously damaged and coated with electrogenerated nanoclusters and so becomes strongly passive [29] and needs polishing and electrochemical cleaning and repeated ultrasonication to get ready for reuse, so the reproducibility and repeatability of $\mathrm{Ag}$ anode surface and its nanostructure because of irreversible structural damages and defects under applied current density are significantly decreased and we see no similarity between SEM images of Ag@C $\mathrm{SH}$ NCs.

3.2. Electrochemical Analysis. In order to check the possibility of any electrochemical reaction occurring in the electrolyte solution (i.e., $\mathrm{C}_{6} \mathrm{SH}+\mathrm{NaBH}_{4}+\mathrm{KCl}+\mathrm{EtOH}$ ), the cyclic voltammetric experiments were carried out at an $\mathrm{Ag}$ rod, a glassy carbon electrode (GCE), and a Pt electrode, as working electrodes, and the results are shown in Figures 2(a), 2(b), and 2(c), respectively. These experiments were carried out under nitrogen purge before electrochemical synthesis, using the optimized electrosynthesis protocol at three different scan rates (i.e., $25 \mathrm{mVs}^{-1}$, green; $50 \mathrm{mVs}^{-1}$, blue; $100 \mathrm{mVs}^{-1}$, red). As is quite obvious from Figure 2, no measurable redox peaks were observed at the surface of the electrodes used, over the electrochemical windows studied, confirming that no electrochemical reaction occurred in the electrolyte solution. The 
TABLE 1: $\mathbf{L}_{\mathbf{8}}$ design of experiments for electrochemical synthesis of $\mathrm{Ag} @ \mathrm{C}_{6} \mathrm{SH}$ NCs.

\begin{tabular}{|c|c|c|}
\hline \multicolumn{3}{|c|}{$\mathrm{TC}_{1}$ : trial condition 1 (randomly selected order 6 ) } \\
\hline Current density $\left(\mathrm{A} \cdot \mathrm{cm}^{-2}\right)$ & 0.5 & 1 \\
\hline Time (Min) & 15 & 1 \\
\hline Distance (mm) & Minimum & 1 \\
\hline Hexanethiol concentration (mM) & 10 & 1 \\
\hline Solvent ratio $=V_{\mathrm{EtOH}} / V_{\mathrm{KCl}}+V_{\mathrm{NaBH}_{4}}$ & $50: 50$ & 1 \\
\hline Temperature & 55 & 1 \\
\hline $\mathrm{NaBH}_{4}(\mathrm{w} / \mathrm{v} \%)$ & $0 \%$ & 1 \\
\hline \multicolumn{3}{|c|}{$\mathrm{TC}_{2}:$ trial condition 2 (randomly selected order 4$)$} \\
\hline Current density $\left(\mathrm{A} \cdot \mathrm{cm}^{-2}\right)$ & 0.5 & 1 \\
\hline Time (Min) & 15 & 1 \\
\hline Distance $(\mathrm{mm})$ & Minimum & 1 \\
\hline Hexanethiol concentration (mM) & 20 & 2 \\
\hline Solvent ratio & $70: 30$ & 2 \\
\hline Temperature & 75 & 2 \\
\hline $\mathrm{NaBH}_{4}(\mathrm{w} / \mathrm{v} \%)$ & $1 \%$ & 2 \\
\hline \multicolumn{3}{|c|}{$\mathrm{TC}_{3}:$ trial condition 3 (randomly selected order 5 ) } \\
\hline Current density $\left(\mathrm{A} \cdot \mathrm{cm}^{-2}\right)$ & 0.5 & 1 \\
\hline Time (Min) & 30 & 2 \\
\hline Distance $(\mathrm{mm})$ & Maximum & 2 \\
\hline Hexanethiol concentration (mM) & 10 & 1 \\
\hline Solvent ratio $=V_{\mathrm{EtOH}} / V_{\mathrm{KCl}}+V_{\mathrm{NaBH}_{4}}$ & $50: 50$ & 1 \\
\hline Temperature $\left({ }^{\circ} \mathrm{C}\right)$ & 75 & 2 \\
\hline $\mathrm{NaBH}_{4}(\mathrm{w} / \mathrm{v} \%)$ & $1 \%$ & 2 \\
\hline \multicolumn{3}{|c|}{$\mathrm{TC}_{4}$ : trial condition 4 (randomly selected order 2 ) } \\
\hline Current density $\left(\mathrm{A} \cdot \mathrm{cm}^{-2}\right)$ & 0.5 & 1 \\
\hline Time (Min) & 30 & 2 \\
\hline Distance (mm) & Maximum & 2 \\
\hline Hexanethiol concentration (mM) & 20 & 2 \\
\hline Solvent ratio $=V_{\mathrm{EtOH}} / V_{\mathrm{KCl}}+V_{\mathrm{NaBH}_{4}}$ & $70: 30$ & 2 \\
\hline Temperature $\left({ }^{\circ} \mathrm{C}\right)$ & 55 & 1 \\
\hline $\mathrm{NaBH}_{4}(\mathrm{w} / \mathrm{v} \%)$ & $0 \%$ & 1 \\
\hline \multicolumn{3}{|c|}{$\mathrm{TC}_{5}$ : trial condition 5 (randomly selected order 7 ) } \\
\hline Current density $\left(\mathrm{A} \cdot \mathrm{cm}^{-2}\right)$ & 0.9 & 2 \\
\hline Time (Min) & 15 & 1 \\
\hline Distance (mm) & Maximum & 2 \\
\hline Hexanethiol concentration (mM) & 10 & 1 \\
\hline Solvent ratio $=V_{\mathrm{EtOH}} / V_{\mathrm{KCl}}+V_{\mathrm{NaBH}_{4}}$ & $70: 30$ & 2 \\
\hline Temperature $\left({ }^{\circ} \mathrm{C}\right)$ & 55 & 1 \\
\hline $\mathrm{NaBH}_{4}(\mathrm{w} / \mathrm{v} \%)$ & $1 \%$ & 2 \\
\hline \multicolumn{3}{|c|}{$\mathrm{TC}_{6}$ : trial condition 6 (randomly selected order 3 ) } \\
\hline Current density $\left(\mathrm{A} \cdot \mathrm{cm}^{-2}\right)$ & 0.9 & 2 \\
\hline Time (Min) & 15 & 1 \\
\hline Distance $(\mathrm{mm})$ & Maximum & 2 \\
\hline Hexanethiol concentration (mM) & 20 & 2 \\
\hline Solvent ratio $=V_{\mathrm{EtOH}} / V_{\mathrm{KCl}}+V_{\mathrm{NaBH}_{4}}$ & $50: 50$ & 1 \\
\hline Temperature $\left({ }^{\circ} \mathrm{C}\right)$ & 75 & 2 \\
\hline $\mathrm{NaBH}_{4}(\mathrm{w} / \mathrm{v} \%)$ & $0 \%$ & 1 \\
\hline \multicolumn{3}{|c|}{$\mathrm{TC}_{7}$ : trial condition 6 (randomly selected order 4$)$} \\
\hline Current density $\left(\mathrm{A} \cdot \mathrm{cm}^{-2}\right)$ & 0.9 & 2 \\
\hline Time (Min) & 30 & 2 \\
\hline Distance $(\mathrm{mm})$ & Minimum & 1 \\
\hline Hexanethiol concentration (mM) & 10 & 1 \\
\hline Solvent ratio $=V_{\mathrm{EtOH}} / V_{\mathrm{KCl}}+V_{\mathrm{NaBH}_{4}}$ & $70: 30$ & 2 \\
\hline
\end{tabular}

TABle 1: Continued.

\begin{tabular}{lcc}
\hline Temperature $\left({ }^{\circ} \mathrm{C}\right)$ & 75 & 2 \\
$\mathrm{NaBH}_{4}(\mathrm{w} / \mathrm{v} \%)$ & $0 \%$ & 1 \\
\hline \multicolumn{2}{c}{$\mathrm{TC}_{8}:$ trial condition 6 (randomly selected order 1$)$} & \\
\hline Current density $\left(\mathrm{A} \cdot \mathrm{cm}^{-2}\right)$ & 0.9 & 2 \\
Time $(\mathrm{Min})$ & 30 & 2 \\
Distance $(\mathrm{mm})$ & Minimum & 1 \\
Hexanethiol concentration $(\mathrm{mM})$ & 20 & 2 \\
Solvent ratio $=V_{\mathrm{EtOH}} / V_{\mathrm{KCl}}+V_{\mathrm{NaBH}_{4}}$ & $50: 50$ & 1 \\
Temperature $\left({ }^{\circ} \mathrm{C}\right)$ & 75 & 1 \\
$\mathrm{NaBH}_{4}(\mathrm{w} / \mathrm{v} \%)$ & $1 \%$ & 2 \\
\hline
\end{tabular}

$\mathrm{CV}$ results revealed that the nature of working electrode has no significant effect on the electrochemical behavior of the electrolyte solution used, before starting the electrosynthesis procedure which is so desired. Meanwhile, it should be noted that the observed small current changes observed should be attributed to the possible impurity residuals and remaining oxygen gas dissolved in the solution.

\subsection{Optimization of Electrosynthesis Process by Taguchi} Methodology. The use of fractional factorial experiments, that is, the Taguchi robust design, leads to the effective reduction of trial numbers required for parameters optimization $[34,35]$. Furthermore, the statistical experiment design in comparison with the sequential design provides the possibility of extracting more information from the resulting experimental data. The Taguchi methodology, as a statistical method, is utilizing a series of orthogonal arrays depending on the number of studied parameters and their levels whose results might be analyzed via the well-known mathematical processes. This methodology permits calculating the average effect of the studied factors at their preselected levels independently [36-38].

In this work, the Taguchi robust design was used to optimize the electrosynthesis process and identify the effects of different parameters on the size (and possibly shape) of the silver nanoclusters. The studied parameters (i.e., current density, electrolysis time, electrode distance, hexanethiol concentration, solvent ratio, $\% \mathrm{NaBH}_{4}$, and temperature) and their levels used for the electrosynthesis of $\mathrm{Ag} @ \mathrm{C}_{6} \mathrm{SH} \mathrm{NCs}$ as 8 different experiments designed are given in Table 1. Moreover, in Figure 3, a sample chronopotentiogram obtained during the 1st cycle of electrosynthesis of $\mathrm{Ag} @ \mathrm{C}_{6} \mathrm{SH} \mathrm{NCs}$ based on trial condition $\mathrm{TC}_{8}$ is shown. As it is seen, up to $125 \mathrm{~s}$, a gradual decrease of potential is observed which is followed by a linearly increased potential between 125 and $550 \mathrm{~s}$, clearly a sign for the beginning of electrochemical reaction. The SEM images of the $\mathrm{Ag}_{0} \mathrm{C}_{6}-\mathrm{SH}$ NCs prepared under the above-mentioned experimental designs (i.e., $\mathrm{TC}_{1}-$ $\mathrm{TC}_{8}$ ) are also shown in Figure 4.

Qualitative analyses of SEM images $\mathrm{TC}_{1}$ to $\mathrm{TC}_{8}$ based on different descriptive criteria including nanometric porosity density (NMPD), agglomeration and aggregation (AA), approximate average agglomeration number (AAAN), approximate average particle size (AAPS), electrochemical response (ECR), electrochemical reaction kinetics (ECRK), 


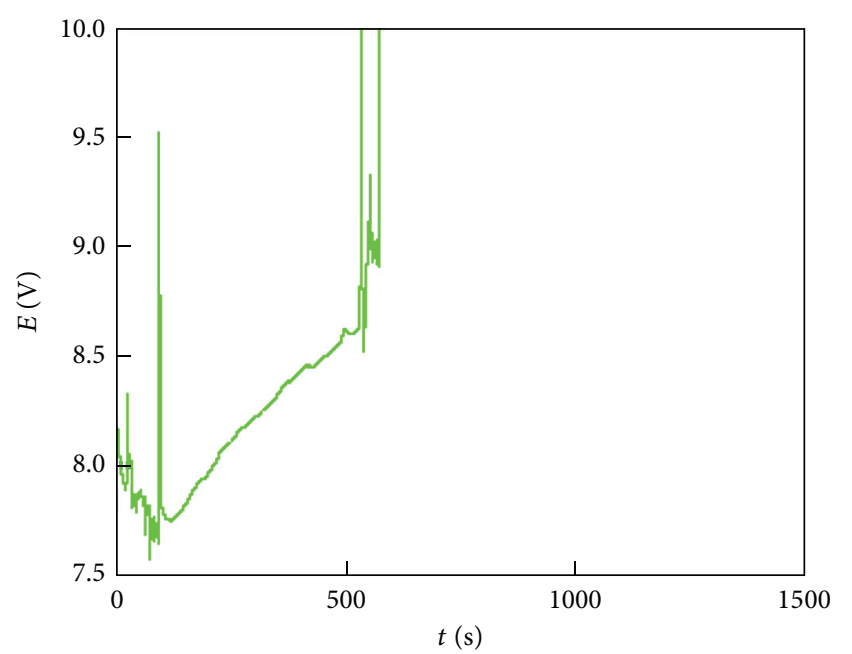

Figure 3: Ag-Pt chronopotentiogram obtained during 1st cycle of electrosynthesis of Ag@ $\mathrm{C}_{6} \mathrm{SH}$ NCs in trial $\mathrm{TC}_{8}$.

and surface roughness of as-prepared samples were carried out and the results are summarized in Table 2. Finally, the approximate estimated size distribution of $\mathrm{TC}_{1}$ to $\mathrm{TC}_{8}$ for 20 estimations within the same feature size of SEM images was evaluated and shown in Table 3.

The orthogonal $\mathbf{L}_{\mathbf{8}}$ array design and average particle size of the electrosynthesized silver nanoclusters are shown in Table 4, the last column of which showing the average diameter of silver nanoparticles obtained at different conditions based on image analysis. Furthermore, the average values of each level corresponding to the studied factors were computed and the results are presented in Table 5. In fact, the table reveals the variation of silver particle's diameter by the changes in the levels of the studied factors. Analysis of variance (ANOVA) was carried out to determine the significance of the studied parameters on the size of the electrosynthesized Ag@C 6 SH NCs.

As it could be seen in Table 6, the results of ANOVA (at $90 \%$ confidence interval) for the performed experiments indicated that, except for hexanethiol concentration, solvent ratio, and temperature, all other variables (i.e., current density, electrolysis time, electrode distance, and $\mathrm{NaBH}_{4} \%$ ) have significant effects on tuning the diameter of silver nanoclusters. Therefore, investigation of the significant factors for preparation of silver nanoclusters with the smallest diameter showed that the optimum conditions of electrochemical synthesis are as a current density of $0.5 \mathrm{~A} \cdot \mathrm{cm}^{-2}$, an electrolysis time of $30 \mathrm{~min}, \mathrm{a} \mathrm{NaBH}_{4}$ amount of $\% 1(\mathrm{w} / \mathrm{v})$, and the possible maximum distance between working electrode and counter electrode. The Taguchi experiment design permits the prediction of the optimum performance (here, electrosynthesis of Ag@C 6 -SH NCs with the smallest possible diameter) by the following expression [39]:

$$
\begin{aligned}
Y_{\mathrm{opt}}= & \frac{T}{N}+\left(C_{d}-\frac{T}{N}\right)+\left(t_{e}-\frac{T}{N}\right)+\left(E_{d}-\frac{T}{N}\right) \\
& +\left(R_{P}-\frac{T}{N}\right) .
\end{aligned}
$$

In this expression, $Y_{\text {opt }}$ is the size of silver nanoclusters at optimum conditions and $T / N$ is the average size of silver nanoclusters obtained via all experiments together with the contributions of $C_{d}, t_{e}, E_{d}$, and $R_{P}$ parameters at optimum levels, where $T$ is the grand total of all silver nanoclusters sizes, $N$ is the total number of experiments, and $C_{d}, t_{e}, E_{d}$, and $R_{P}$ are optimum current density, electrolysis time, the distance between working electrode and counter electrode, and percent of $\mathrm{NaBH}_{4}$, respectively. Meanwhile, the confidence interval (CI) for the predicted size of silver nanoclusters at optimum conditions could be obtained by [40]

$$
\mathrm{CI}= \pm \sqrt{\frac{F_{\alpha}\left(f_{1}, f_{2}\right) \cdot V_{e}}{n_{e}}}
$$

where $V_{e}$ is the variance of error term, $F_{\alpha}\left(f_{1}, f_{2}\right)$ is the variance ratio for degree of freedom (DOF), $f_{1}$ and $f_{2}$ are at the level of significance of $\alpha$ (here, $\alpha=90 \%$ ), and $f_{1}$ is DOF of mean (which always equals 1 ), $f_{2}$ is DOF of the error term, and $n_{e}$ is the number of equivalent replications, which could be computed as follows:

$$
n_{e}=\frac{\text { Number of trials }}{\text { DOF of mean (always } 1)+ \text { DOF of all factors used in estimation }}
$$

The calculations showed that the estimated size of silver nanoclusters at optimum conditions will be about $30.5 \pm$ $2.0 \mathrm{~nm}$. On the other hand, as could be seen in Table 6 , the third trial in this table contains the optimum conditions proposed by ANOVA $\left(0.5 \mathrm{~A} \cdot \mathrm{cm}^{-2}\right.$ as the current density, $30 \mathrm{~min}$ as process time, the possible maximum distance between working electrode and counter electrode, and usage of $1 \%$ of $\mathrm{NaBH}_{4}$ ) for preparation of $\mathrm{Ag} @ \mathrm{C}_{6} \mathrm{SH} \mathrm{NCs}$ via electrochemical method which is in sufficient agreement in practice. SEM image of $\mathrm{TC}_{3}$ as the best electrosynthesized sample revealed that the synthesized tetrahedral and triangular silver nanoclusters particles at these conditions (trial $\mathrm{TC}_{3}$ ) have about $30 \mathrm{~nm}$ average size (Figure 3), which is in agreement with the estimated range for size of silver nanoclusters at the optimum conditions of electrochemical reaction (i.e., $30.5 \pm 2.0 \mathrm{~nm}$ ). Thereafter, silver nanoclusters prepared at these optimum conditions (trial 3) were used for more characterization studies such as UV-Vis analysis and XRD.

3.4. UV-Vis Surface Plasmon Bands. The solutions of colloidal nanoparticles of silver have a very distinctive color 


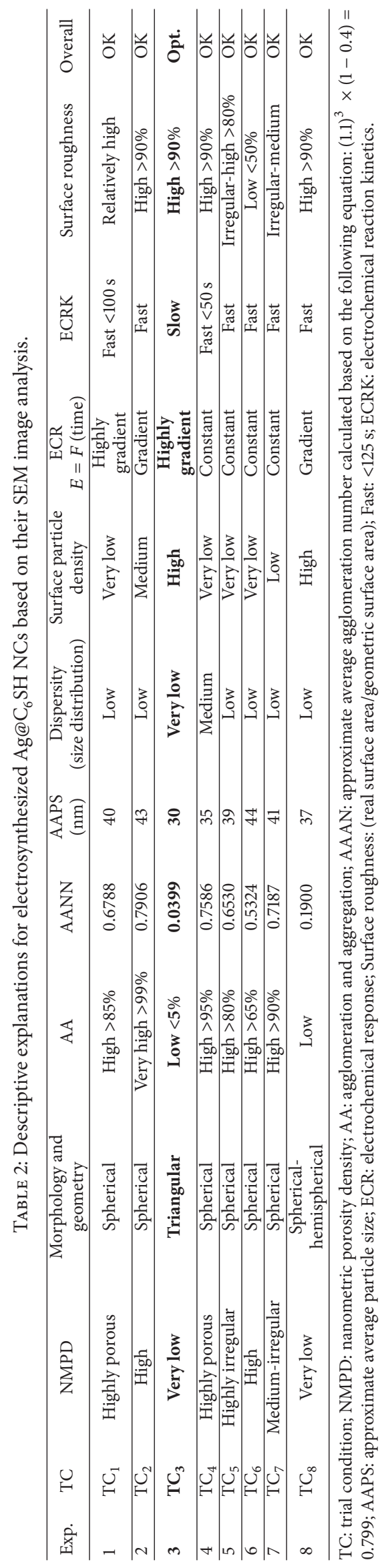




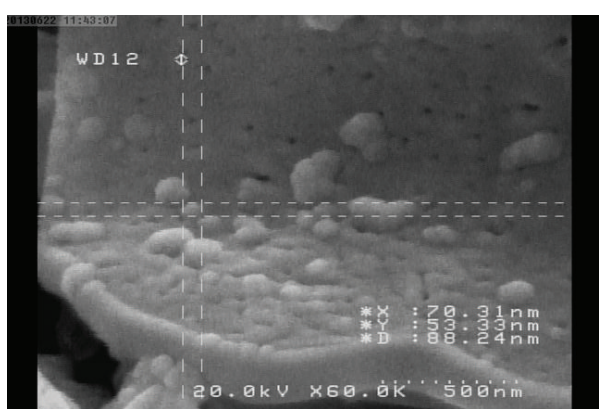

$\mathrm{TC}_{2}$

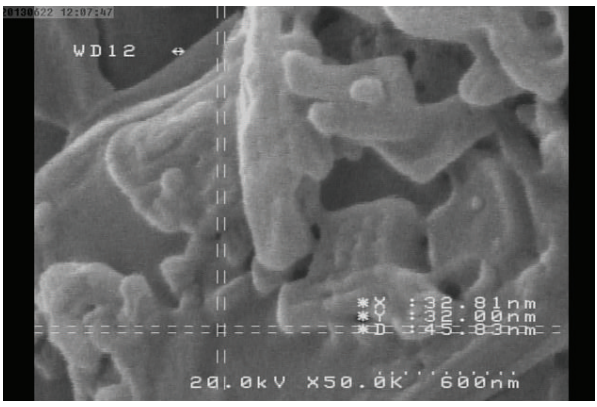

$\mathrm{TC}_{4}$

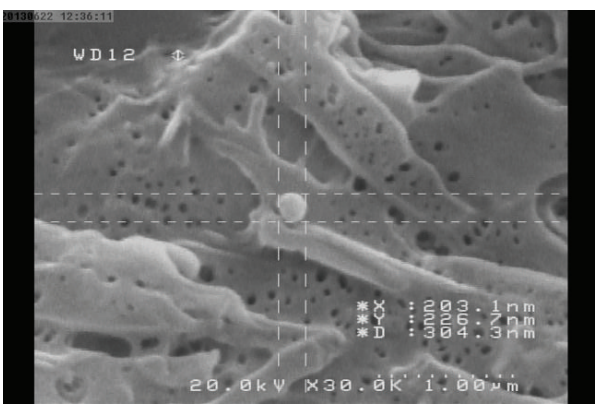

$\mathrm{TC}_{6}$

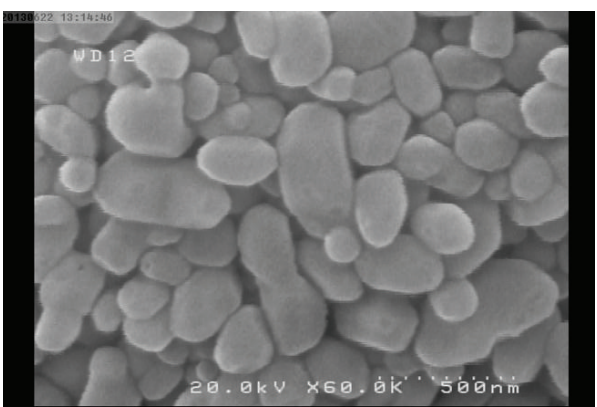

$\mathrm{TC}_{8}$

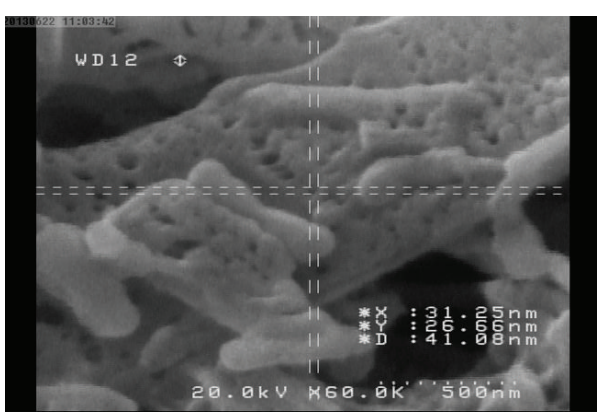

$\mathrm{TC}_{1}$

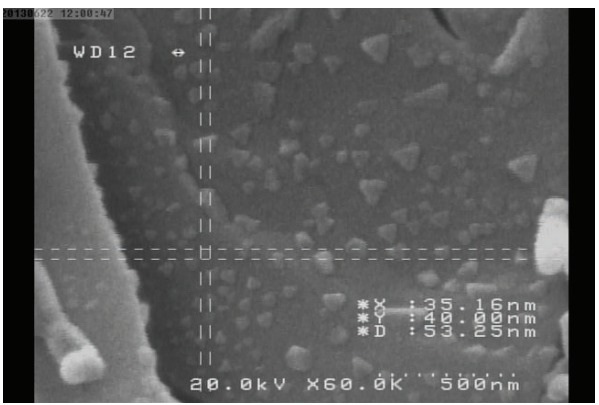

$\mathrm{TC}_{3}$

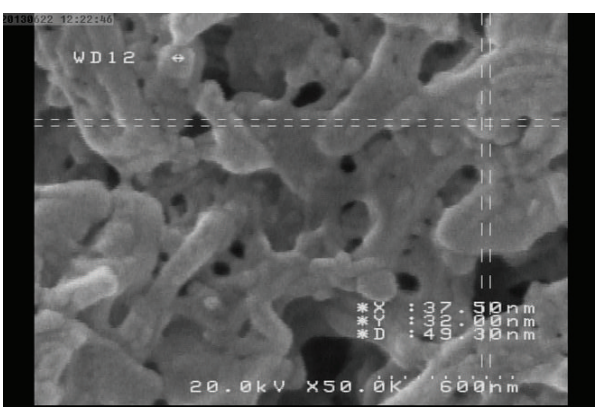

$\mathrm{TC}_{5}$

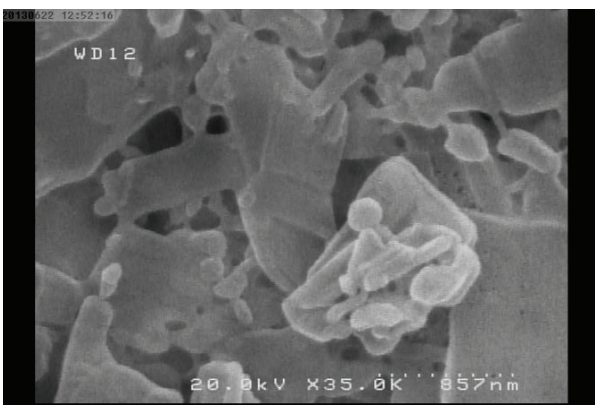

$\mathrm{TC}_{7}$

FIgURE 4: SEM images of the electrosynthesized Ag@ $\mathrm{C}_{6} \mathrm{SH}$ NCs based on Taguchi-DOE under optimized electrosynthesis conditions.

which arises from the tiny dimension of the silver particles. The resonance of nanoparticles, known as surface plasmon absorbance (SPR), could be used as an analytical tool to reveal the characteristic of some mesoscale surfaces [41]. The SPR band of the as-prepared Ag@C $\mathrm{C}_{6} \mathrm{SH}$ NCs in toluene was observed using a UV-Vis spectrophotometer (COMPAC). Figure 5 represents the UV-Vis spectrum of electrosynthesized nanoclusters dispersion in toluene at a current density of $0.5 \mathrm{~A} \cdot \mathrm{cm}^{-2}$. As it is seen, the silver nanoclusters depending on their size regime $(<10 \mathrm{~nm})$ and level of monodispersity may show an absorption peak at around 300-400 $\mathrm{nm}$ that is characteristic of SPR band of Ag nanoparticles. It should be considered that the presence of trace chromophore impurities like phase transfer catalyst (in chemical synthesis), free unattached thiols on the core surface, and so on absolutely will affect the response and also shift the peaks. 

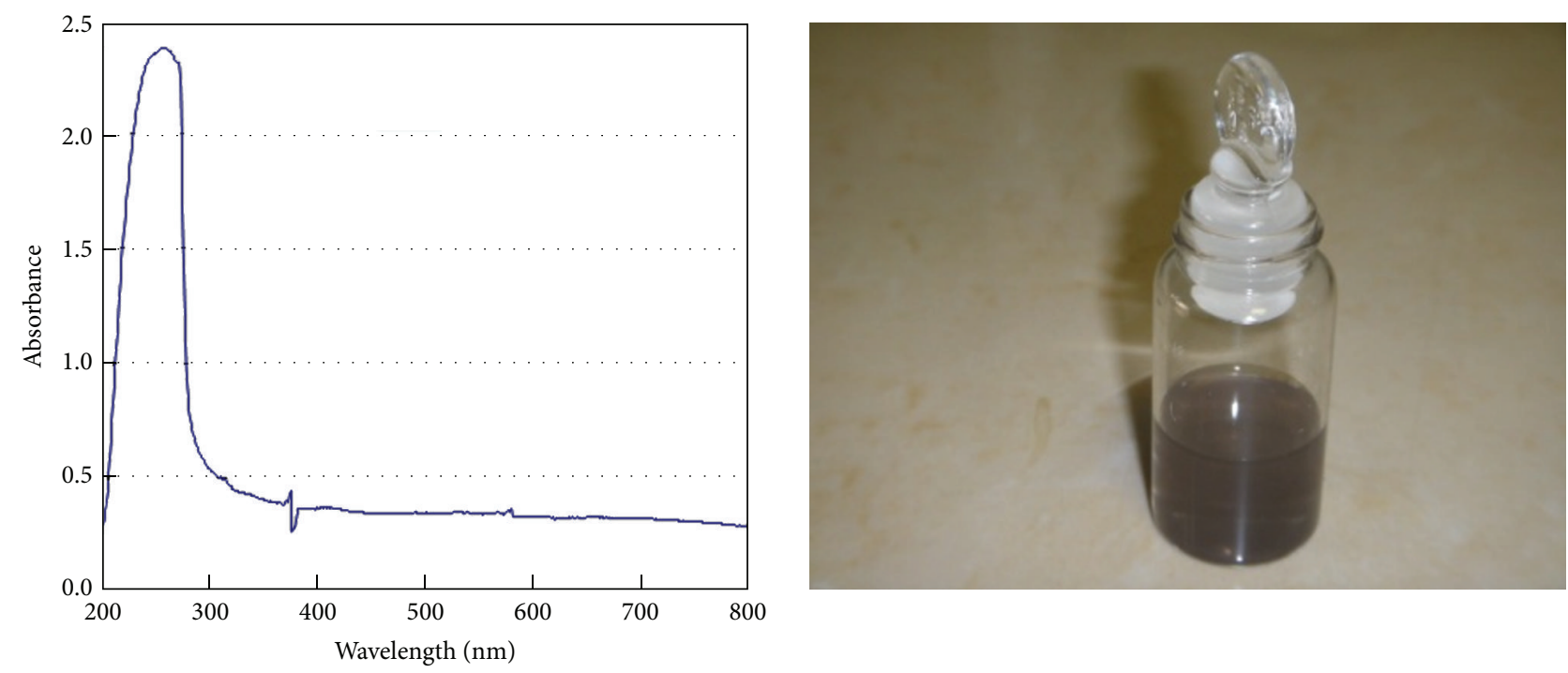

FIGURE 5: UV-Vis absorbance of the electrosynthesized Ag@ $\mathrm{C}_{6} \mathrm{SH}$ NCs dispersed in toluene.

TABLE 3: Approximate estimated size distribution of $\mathrm{TC}_{1}$ to $\mathrm{TC}_{8}$ for 20 estimations only based on the feature size of SEM images.

\begin{tabular}{lcccccccc}
\hline Number & $\mathrm{TC}_{1}$ & $\mathrm{TC}_{2}$ & $\mathrm{TC}_{3}$ & $\mathrm{TC}_{4}$ & $\mathrm{TC}_{5}$ & $\mathrm{TC}_{6}$ & $\mathrm{TC}_{7}$ & $\mathrm{TC}_{8}$ \\
\hline 1 & 57 & 48 & 33 & 51 & 40 & 47 & 45 & 39 \\
2 & 51 & 49 & 38 & 34 & 41 & 41 & 40 & 38 \\
3 & 50 & 45 & 32 & 39 & 30 & 40 & 34 & 40 \\
4 & 30 & 49 & 36 & 45 & 49 & 40 & 40 & 45 \\
5 & 35 & 38 & 29 & 38 & 40 & 45 & 42 & 38 \\
6 & 51 & 46 & 38 & 34 & 41 & 51 & 45 & 39 \\
7 & 45 & 48 & 31 & 36 & 38 & 45 & 45 & 36 \\
8 & 51 & 45 & 28 & 34 & 30 & 41 & 44 & 30 \\
9 & 21 & 45 & 26 & 29 & 32 & 50 & 38 & 34 \\
10 & 39 & 43 & 35 & 44 & 32 & 37 & 46 & 30 \\
11 & 27 & 37 & 31 & 29 & 40 & 49 & 33 & 36 \\
12 & 55 & 50 & 31 & 33 & 48 & 45 & 43 & 42 \\
13 & 30 & 40 & 23 & 29 & 47 & 40 & 41 & 43 \\
14 & 37 & 42 & 27 & 35 & 45 & 47 & 40 & 43 \\
15 & 32 & 35 & 24 & 31 & 30 & 32 & 32 & 30 \\
16 & 28 & 39 & 24 & 30 & 32 & 49 & 43 & 30 \\
17 & 39 & 39 & 30 & 29 & 38 & 43 & 40 & 32 \\
18 & 33 & 38 & 27 & 30 & 28 & 49 & 45 & 30 \\
19 & 52 & 45 & 28 & 40 & 53 & 42 & 40 & 41 \\
20 & 37 & 39 & 29 & 30 & 46 & 47 & 44 & 44 \\
Average size (nm) & 40 & 43 & 30 & 35 & 39 & 44 & 41 & 37 \\
SD & 10 & 5 & 4 & 6 & 7 & 5 & 4 & 5 \\
CV (\%) & 26 & 11 & 15 & 18 & 19 & 11 & 10 & 14 \\
\hline & & & & & & & &
\end{tabular}

Irreversible and inevitable aggregation and agglomeration competing phenomena will certainly influence the nanostructure of sample and need more purification and fractionation dispersion after treatments. SPR absorbance spectra of the metal nanoparticles are sensitive to the changes in core size, especially in the metal-to-molecule size range.
Based on our reported SEM image size $(30 \mathrm{~nm})$, it is evident that SPR peaks will be observed here with so much difficulty.

For silver nanoparticles, the intensity and wavelength of SPR band depend on the size being intense and sharp for larger nanoparticles $\left(>2 \mathrm{~nm}\right.$ ) with $\lambda_{\max }$ at $\sim 420 \mathrm{~nm}$ and at decreased (1-2 nm) core diameter becoming less intense and broadened and shifting to lower energy. It was found that there is a variation of about $10 \mathrm{~nm}$ in the peak wavelength for the nanoparticles prepared at different current densities (i.e., 0.5 to $0.9 \mathrm{~A} \cdot \mathrm{cm}^{-2}$ ) and different hexanethiol concentrations (10 to $20 \mathrm{mM}$ ). The SPR band of the freshly prepared sample and the redissolved dried sample in toluene is similar which shows the formation of very stable nanoparticles (even after 12 months). It is interesting to note that SEM images of the $\mathrm{Ag} @ \mathrm{C}_{6}-\mathrm{SH}$ NCs electrosynthesized under optimized conditions $\left(\mathrm{TC}_{3}\right.$ ) clearly revealed its triangular pyramidal structure (Figure 4). Such triangular Ag nanotriangles fabricated by solution-phase nanosphere lithography have already been reported in the literature [42].

3.5. XRD Analysis. Figure 6 shows the typical XRD pattern of the prepared stabilized nanoparticles, compared with the reported one [43]. Five distinct diffraction peaks are observed at $2 \theta$ values of $38.158,44.344,64.507,77.458$, and 81.580, which can be indexed to (111), (200), (220), (311), and (222) crystalline planes of cubic pure silver, respectively. The broad nature of the XRD peaks is attributed to the nanometric size of the particles. The pattern confirms that the main composition of the nanoparticles is silver. It is also found that there are some little peaks compatible with the standard XRD pattern of $\mathrm{Ag}_{2} \mathrm{CO}_{3}$. The formation of silver carbonate may be attributed to the presence of carbon dioxide in the atmosphere. Therefore, the product should be preserved in airproof conditions. Table 7 shows the calculated size of asprepared Ag@ $\mathrm{C}_{6}-\mathrm{SH}$ NCs size based on Scherer equation PXRD-based data. 


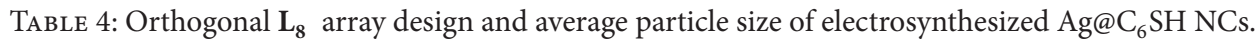

\begin{tabular}{|c|c|c|c|c|c|c|c|c|}
\hline Trial & $\begin{array}{l}\text { Current density } \\
\left(\mathrm{A} \cdot \mathrm{cm}^{-2}\right)\end{array}$ & $\begin{array}{l}\text { Time } \\
(\text { Min) }\end{array}$ & $\begin{array}{c}\text { Distance } \\
(\mathrm{mm})\end{array}$ & $\begin{array}{c}\text { Thiol conc. } \\
(\mathrm{mM})\end{array}$ & Solvent ratio & $\begin{array}{l}\text { Temp. } \\
\left({ }^{\circ} \mathrm{C}\right)\end{array}$ & $\begin{array}{l}\mathrm{NaBH}_{4} \\
(\mathrm{w} / \mathrm{v} \%) \\
\end{array}$ & $\begin{array}{c}\text { Average size } \\
(\mathrm{nm})\end{array}$ \\
\hline 1 & 0.5 & 15 & Min. & 10 & $50: 50$ & 55 & 0 & $40(10)$ \\
\hline 2 & 0.5 & 15 & Min. & 20 & $70: 30$ & 75 & 1 & $43(4)$ \\
\hline 3 & 0.5 & 30 & Max. & 10 & $50: 50$ & 75 & 1 & $30(4)$ \\
\hline 4 & 0.5 & 30 & Max. & 20 & $70: 30$ & 55 & 0 & $35(6)$ \\
\hline 5 & 0.9 & 15 & Max. & 10 & $70: 30$ & 55 & 1 & $39(7)$ \\
\hline 6 & 0.9 & 15 & Max. & 20 & $50: 50$ & 75 & 0 & $44(5)$ \\
\hline 7 & 0.9 & 30 & Min. & 10 & $70: 30$ & 75 & 0 & $41(4)$ \\
\hline 8 & 0.9 & 30 & Min. & 20 & $50: 50$ & 55 & 1 & $37(5)$ \\
\hline
\end{tabular}
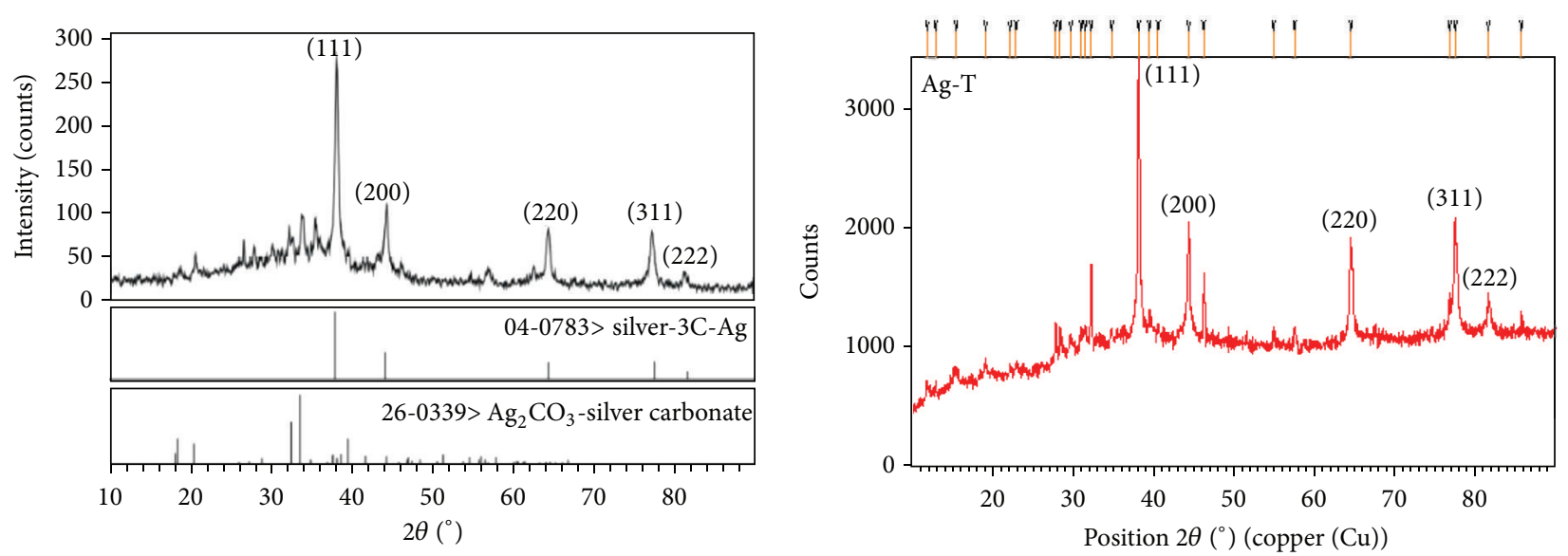

XRD pattern of the silver nanoparticles

FIgURE 6: Powder XRD pattern of as-prepared Ag@ $\mathrm{C}_{6} \mathrm{SH}$ NCs (right) and standard XRD (left) [43].

TABLE 5: Average values of particle size corresponding to the effect of factors at studied levels.

\begin{tabular}{lcc}
\hline Factor & Level 1 $(\mathrm{nm})$ & Level 2 $(\mathrm{nm})$ \\
\hline Current density $\left(\mathrm{A} \cdot \mathrm{cm}^{-2}\right)$ & 38.3 & 40.3 \\
Time $(\mathrm{s})$ & 42.8 & 35.8 \\
Distance $(\mathrm{mm})$ & 41.5 & 37.0 \\
Thiol concentration $(\mathrm{mM})$ & 38.8 & 39.8 \\
Solvent ratio & 39.0 & 39.5 \\
Temperature $\left({ }^{\circ} \mathrm{C}\right)$ & 39.0 & 39.5 \\
$\% \mathrm{NaBH}_{4}$ & 41.3 & 37.3 \\
\hline
\end{tabular}

\section{Conclusions}

A facile electrochemical procedure, based on the dissolution of a metallic silver rod anode in a protic solvent (EtOH), was successfully used to obtain silver nanoclusters capped by hexanethiol with average sizes ranging from 30 to $44 \mathrm{~nm}$ based on SEM images estimation. The prepared nanoclusters were stabilized by the aid of hexanethiol $\left(\mathrm{C}_{6} \mathrm{SH}\right)$. By precisely tuning the process parameters, it was possible to obtain silver with different particle sizes and shapes. Characterization of the electrosynthesized nanoparticles was carried out by SEM, XRD, and UV-Vis spectroscopy. Meanwhile,
TABLE 6: Results of ANOVA for Ag@ $\mathrm{C}_{6} \mathrm{SH}$ NCs through electrochemical synthesis using $\mathbf{L}_{\mathbf{8}}\left(2^{7}\right)$ matrix.

\begin{tabular}{|c|c|c|c|c|c|c|c|}
\hline \multirow{2}{*}{ Factor } & \multirow{2}{*}{ DOF } & \multirow{2}{*}{$S$} & \multirow{2}{*}{$V$} & \multicolumn{4}{|c|}{ Pooled } \\
\hline & & & & DOF & $S^{\prime}$ & $F^{\prime}$ & $P^{\prime}(\%)^{\mathrm{a}}$ \\
\hline Current density $\left(C_{d}\right)$ & 1 & 8.0 & 8.0 & 1 & 8.0 & 8.0 & 3.9 \\
\hline Time $\left(t_{e}\right)$ & 1 & 98.0 & 98.0 & 1 & 98.0 & 98.0 & 53.4 \\
\hline Distance $\left(E_{d}\right)$ & 1 & 40.5 & 40.5 & 1 & 40.5 & 40.5 & 21.8 \\
\hline $\begin{array}{l}\text { Hexanethiol } \mathrm{C}_{6} \mathrm{SH} \\
\text { concentration }\end{array}$ & 1 & 2.0 & 2.0 & - & - & - & - \\
\hline Solvent ratio $\left(S_{R}\right)$ & 1 & 0.5 & 0.5 & - & - & - & - \\
\hline $\begin{array}{l}\text { Temperature } \\
\text { (Temp.) }\end{array}$ & 1 & 0.5 & 0.5 & - & - & - & - \\
\hline$\% \mathrm{NaBH}_{4}\left(R_{P}\right)$ & 1 & 32.0 & 32.0 & 1 & 32 & 32 & 17.1 \\
\hline Error $(E)$ & 0 & - & - & 3 & 3 & 1 & 3.8 \\
\hline
\end{tabular}

Note: the critical value was for a $90 \%$ confidence level; pooled error resulted from pooling of insignificant effect. a is designated for percentage of contribution.

as evaluated by Taguchi $\mathbf{L}_{\mathbf{8}}$ robust design, it was found that, among different experimental parameters studied, the current density, electrolysis time, electrode distance, and amount of $\mathrm{NaBH}_{4} \%$ have significant effects on the tuning 
TABLE 7: Scherer equation PXRD-based particle size data.

\begin{tabular}{lcccccccc}
\hline hkl & $2 \theta^{\circ}$ & Height & FWHM & $d$-spacing & Rel. int. & $\lambda$ & $D(\mathrm{~nm})$ \\
\hline 111 & 38.158 & 1739 & 0.26 & 2.35655 & 100.00 & 1.540 & 91.63 \\
200 & 44.344 & 696 & 0.32 & 2.04112 & 40.03 & 1.540 & 74.16 \\
220 & 64.507 & 707 & 0.31 & 1.44342 & 40.66 & 1.540 & 76.56 \\
311 & 77.458 & 821 & 0.33 & 1.23123 & 47.25 & 1.540 & 71.92 \\
222 & 81.580 & 225 & 0.43 & 1.17914 & 12.96 & 1.540 & 55.19 \\
\hline
\end{tabular}

$D$ average $=\sum$ (D.I) $/ 5=38.72 \mathrm{~nm}$.

of the diameter and shape of the final silver nanoclusters electrochemically synthesized. The average size of the planar triangular (2D)/pyramidal shape (3D) Ag@ $\mathrm{C}_{6} \mathrm{SH} \mathrm{NCs}$ obtained under optimized experimental conditions $\left(\mathrm{TC}_{3}\right)$ was found to be $30.5 \pm 2.0 \mathrm{~nm}$.

\section{Conflict of Interests}

The authors declare that there is no conflict of interests regarding the publication of this paper.

\section{Acknowledgments}

The authors gratefully acknowledge the support for this work by Research Councils of University of Tehran, K. N. Toosi University of Technology, and Razi University.

\section{References}

[1] H. Bönnemann and K. S. Nagabhushana, "Metal nanoclusters: synthesis and strategies for their size control," in Metal Nanoclusters in Catalysis and Materials Science, B. Corain, G. Schmid, and N. Toshima, Eds., chapter 2, pp. 21-48, Elsevier B.V., New York, NY, USA, 2008.

[2] J. D. Aiken III, Y. Lin, and R. G. Finke, "A perspective on nanocluster catalysis: polyoxoanion and $\left(n-\mathrm{C}_{4} \mathrm{H}_{9}\right)_{4} \mathrm{~N}^{+}$stabilized $\operatorname{Ir}(0)_{\sim 300}$ nanocluster 'soluble heterogeneous catalysts"', Journal of Molecular Catalysis A: Chemical, vol. 114, no. 1-3, pp. 29-51, 1996.

[3] G. Schmid, "Electronic structures of metal clusters and cluster compounds," in Clusters and Colloids: From Theory to Applications, N. Rösch and G. Pacchioni, Eds., chapter 2, pp. 5-88, VCH Publishers, New York, NY, USA, 2007.

[4] L. J. de Jongh, Ed., Physics and Chemistry of Metal Cluster Compounds: Model Systems for Small Metal Particles, Kluwer Academic Publishers, Dordrecht, The Netherlands, 1994.

[5] R. Pool, "Clusters: strange morsels of matter," Science, vol. 248, no. 4960, pp. 1186-1188, 1990.

[6] U. Simon, G. Schön, and G. Schmid, "The application of $\mathrm{Au}_{55}$ clusters as quantum dots," Angewandte Chemie International Edition, vol. 32, no. 2, pp. 250-254, 1993.

[7] J. Glanz, "Computer scientists rethink their discipline's foundations," Science, vol. 269, no. 5229, pp. 1363-1364, 1995.

[8] G. Schön and U. Simon, "A fascinating new field in colloid science: small ligand-stabilized metal clusters and their possible application in microelectronics-part II: future directions," Colloid and Polymer Science, vol. 273, no. 3, pp. 202-218, 1995.
[9] M. Antonietti and C. Göltner, "Superstructures of functional colloids: chemistry on the nanometer scale," Angewandte Chemie (International Edition in English), vol. 36, no. 9, pp. 910928, 1997.

[10] R. Elghanian, J. J. Storhoff, R. C. Mucic, R. L. Letsinger, and C. A. Mirkin, "Selective colorimetric detection of polynucleotides based on the distance-dependent optical properties of gold nanoparticles," Science, vol. 277, no. 5329, pp. 1078-1081, 1997.

[11] V. L. Colvin, M. C. Schlamp, and A. P. Alivisatos, "Lightemitting diodes made from cadmium selenide nanocrystals and a semiconducting polymer," Nature, vol. 370, no. 6488, pp. 354357, 1994.

[12] S. V. Sonti and A. Bose, "Cell separation using protein-A-coated magnetic nanoclusters," Journal of Colloid and Interface Science, vol. 170, no. 2, pp. 575-585, 1995.

[13] M. T. Reetz, M. Winter, G. Dumpich, J. Lohau, and S. Friedrichowski, "Fabrication of metallic and bimetallic nanostructures by electron beam induced metallization of surfactant stabilized $\mathrm{Pd}$ and Pd/Pt clusters," Journal of the American Chemical Society, vol. 119, no. 19, pp. 4539-4540, 1997.

[14] T. Vossmeyer, E. DeIonno, and J. R. Heath, "Light-directed assembly of nanoparticles," Angewandte Chemie International Edition, vol. 36, no. 10, pp. 1080-1083, 1997.

[15] L. Gong, H. Kuai, S. Ren et al., "Ag nanocluster-based labelfree catalytic and molecular beacons for amplified biosensing," Chemical Communications, vol. 51, no. 60, pp. 12095-12098, 2015.

[16] K. Kon, S. M. A. Hakim Siddiki, and K.-I. Shimizu, "Sizeand support-dependent Pt nanocluster catalysis for oxidantfree dehydrogenation of alcohols," Journal of Catalysis, vol. 304, pp. 63-71, 2013.

[17] Y. Lu and W. Chen, "Size effect of silver nanoclusters on their catalytic activity for oxygen electro-reduction," Journal of Power Sources, vol. 197, pp. 107-110, 2012.

[18] K. Shimizu, K. Sawabe, and A. Satsuma, "Unique catalytic features of Ag nanoclusters for selective $\mathrm{NO}_{x}$ reduction and green chemical reactions," Catalysis Science \& Technology, vol. 1, no. 3, pp. 331-341, 2011.

[19] M. Liu and W. Chen, "Green synthesis of silver nanoclusters supported on carbon nanodots: enhanced photoluminescence and high catalytic activity for oxygen reduction reaction," Nanoscale, vol. 5, no. 24, pp. 12558-12564, 2013.

[20] J. Liu, K. S. Krishna, Y. B. Losovyj et al., "Ligand-stabilized and atomically precise gold nanocluster catalysis: a case study for correlating fundamental electronic properties with catalysis," Chemistry-A European Journal, vol. 19, no. 31, pp. 10201-10208, 2013.

[21] W. Dong, L. Zhang, B. Li et al., "Preparation of hollow multiple-Ag-nanoclustes-C-shell nanostructures and their catalytic properties," Applied Catalysis B: Environmental, vol. 180, pp. 13-19, 2016.

[22] E. Gaffet, M. Tachikart, O. El Kedim, and R. Rahouadj, "Nanostructural materials formation by mechanical alloying: morphologic analysis based on transmission and scanning electron microscopic observations," Materials Characterization, vol. 36, no. 4-5, pp. 185-190, 1996.

[23] A. Amulyavichus, A. Daugvila, R. Davidonis, and C. Sipavichus, "Study of chemical composition of nanostructural materials prepared by laser cutting of metals," Fizika Metallov I Metallovedenie, vol. 85, pp. 111-117, 1998.

[24] S. Dhanya, V. Saumya, and T. P. Rao, "Synthesis of silver nanoclusters, characterization and application to trace level 
sensing of nitrate in aqueous media," Electrochimica Acta, vol. 102, pp. 299-305, 2013.

[25] P. Kar, F. Tatard, G. Lamblin et al., "Silver nanoparticles to improve electron transfer at interfaces of gold electrodes modified by biotin or avidin," Journal of Electroanalytical Chemistry, vol. 692, pp. 17-25, 2013.

[26] L. Shang, S. Dong, and G. U. Nienhaus, "Ultra-small fluorescent metal nanoclusters: synthesis and biological applications," Nano Today, vol. 6, no. 4, pp. 401-418, 2011.

[27] H. Xu and K. S. Suslick, "Water-soluble fluorescent silver nanoclusters," Advanced Materials, vol. 22, no. 10, pp. 1078-1082, 2010.

[28] S. Prabhu and E. K. Poulose, "Silver nanoparticles: mechanism of antimicrobial action, synthesis, medical applications, and toxicity effects," International Nano Letters, vol. 2, article 32, 2012.

[29] C. Fernández-Blanco, Á. Colina, and A. Heras, "UV/Vis spectroelectrochemistry as a tool for monitoring the fabrication of sensors based on silver nanoparticle modified electrodes," Sensors, vol. 13, no. 5, pp. 5700-5711, 2013.

[30] Y. Lu and W. Chen, "Size effect of silver nanoclusters on their catalytic activity for oxygen electro-reduction," Journal of Power Sources, vol. 197, pp. 107-110, 2012.

[31] M. Z. Hu and C. E. Easterly, "A novel thermal electrochemical synthesis method for production of stable colloids of "naked" metal (Ag) nanocrystals," Materials Science and Engineering: C, vol. 29, no. 3, pp. 726-736, 2009.

[32] M. T. Reetz, W. Helbig, and S. A. Quaiser, "Electrochemical methods in the synthesis of nanostructured transition metal clusters," in Active Metals: Preparation, Characterization, Applications, A. Fürstner, Ed., chapter 7, Wiley-VCH, New York, NY, USA, 1996.

[33] J. C. Love, L. A. Estroff, J. K. Kriebel, R. G. Nuzzo, and G. M. Whitesides, "Self-assembled monolayers of thiolates on metals as a form of nanotechnology," Chemical Reviews, vol. 105, no. 4, pp. 1103-1170, 2005.

[34] M. Starowicz, B. Stypuła, and J. Banaś, "Electrochemical synthesis of silver nanoparticles," Electrochemistry Communications, vol. 8, no. 2, pp. 227-230, 2006.

[35] P. J. Ross, Taguchi Techniques for Quality Engineering, McGrawHill, New York, NY, USA, 1988.

[36] S. M. Pourmortazavi, S. S. Hajimirsadeghi, M. RahimiNasrabadi, and M. M. Zahedi, "Taguchi robust design to optimize synthesis of lead oxalate nano-disks," Materials Science in Semiconductor Processing, vol. 16, no. 1, pp. 131-137, 2013.

[37] S. M. Pourmortazavi, M. Taghdiri, N. Samimi, and M. RahimiNasrabadi, "Eggshell bioactive membrane assisted synthesis of barium tungstate nanoparticles," Materials Letters, vol. 121, pp. 5-7, 2014.

[38] M. Shamsipur, S. M. Pourmortazavi, S. S. Hajimirsadeghi, and M. Roushani, "Applying Taguchi robust design to the optimization of synthesis of barium carbonate nanorods via direct precipitation," Colloids and Surfaces A: Physicochemical and Engineering Aspects, vol. 423, pp. 35-41, 2013.

[39] G. Taguchi, Systems of Experimental Design, vol. 1-2, Kraus, New York, NY, USA, 1987.

[40] S. M. Pourmortazavi, S. S. Hajimirsadeghi, I. Kohsari, R. F. Alamdari, and M. Rahimi-Nasrabadi, "Determination of the optimal conditions for synthesis of silver oxalate nanorods," Chemical Engineering and Technology, vol. 31, no. 10, pp. 15321535, 2008.
[41] M. Shamsipur, M. Roushani, and S. M. Pourmortazavi, "Electrochemical synthesis and characterization of zinc oxalate nanoparticles," Materials Research Bulletin, vol. 48, no. 3, pp. 1275-1280, 2013.

[42] A. J. Haes, J. Zhao, S. Zou et al., "Solution-phase, triangular Ag nanotriangles fabricated by nanosphere lithography," Journal of Physical Chemistry B, vol. 109, no. 22, pp. 11158-11162, 2005.

[43] J. P. Wilcoxon, T. Martino, E. Klavetter, and A. P. Sylwester, "Synthesis and catalytic properties of metal and semiconductor nanoclusters," in Nanophase Materials, vol. 260 of NATO ASI, pp. 771-780, 1994. 

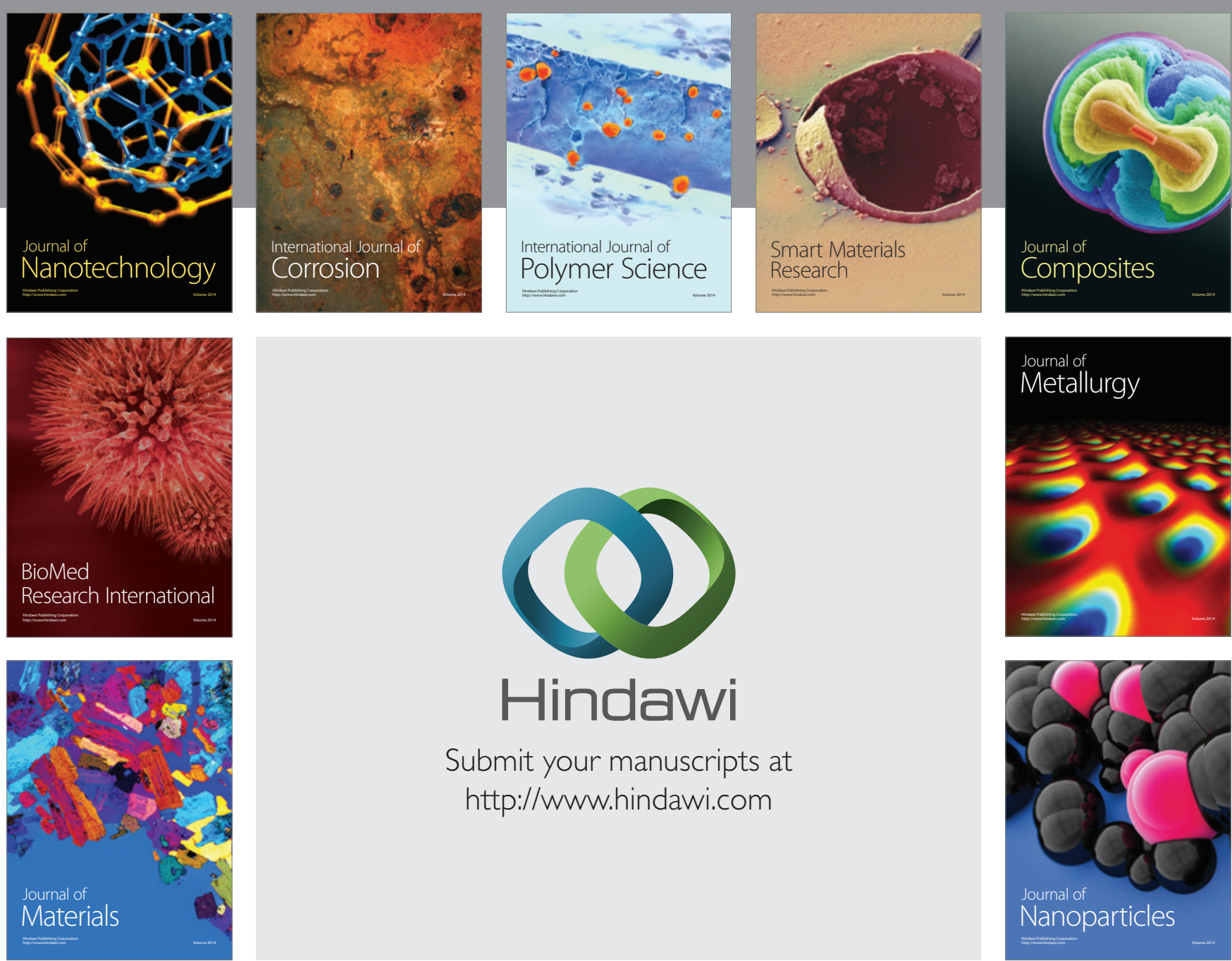

\section{Hindawi}

Submit your manuscripts at

http://www.hindawi.com

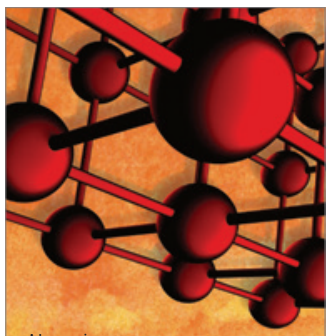

Materials Science and Engineering
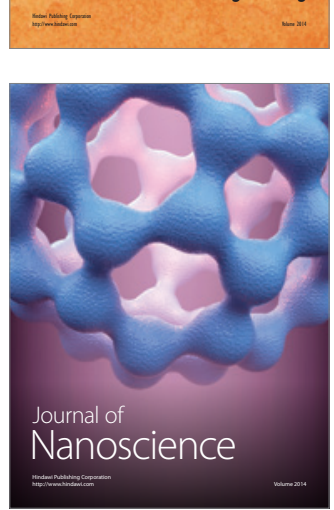
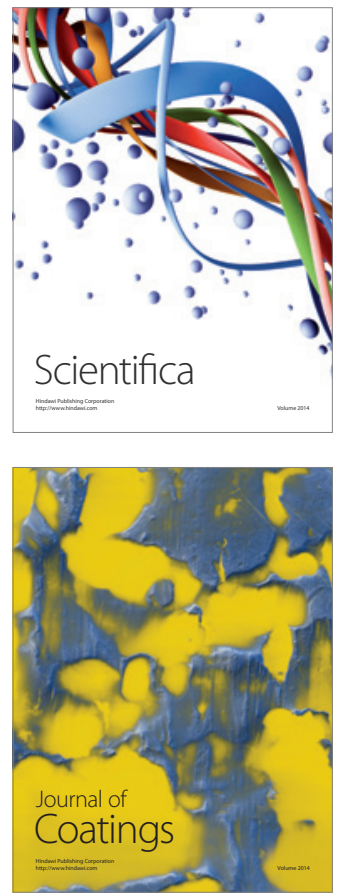
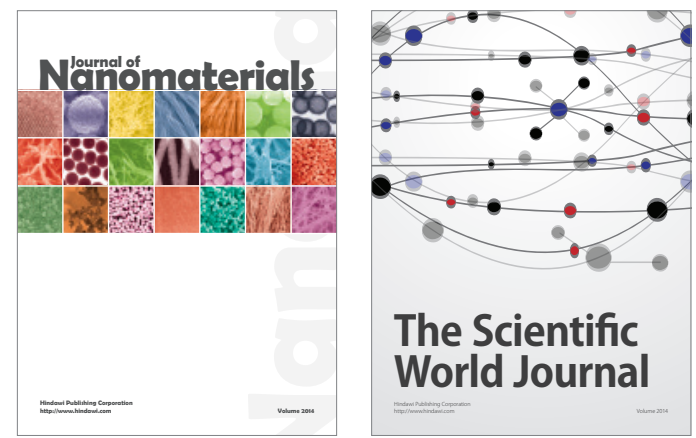

The Scientific World Journal
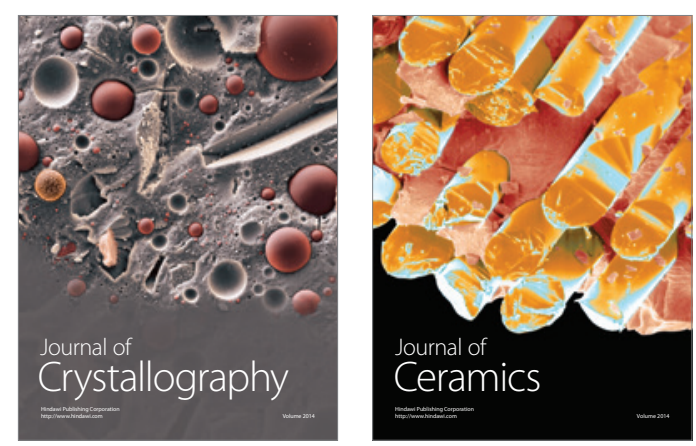
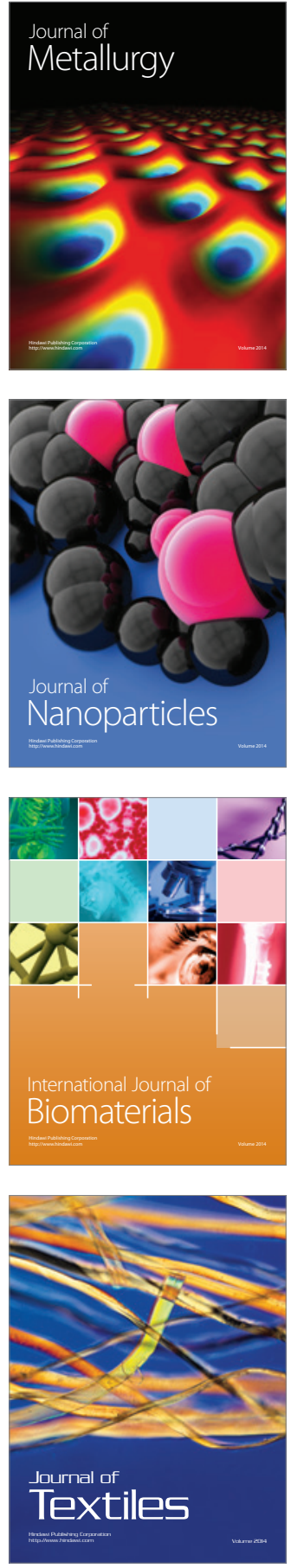